\title{
Longitudinal analyses of CLL in mice identify leukemia-related clonal changes including a Myc gain predicting poor outcome in patients
}

\author{
Selcen Öztürk (D ${ }^{1,7}$, Yashna Paul ${ }^{1,7}$, Saira Afzal (D) ${ }^{2,3}$, Irene Gil-Farina ${ }^{2,3}$, Anna Jauch ${ }^{4}$, Peter-Martin Bruch (D) ${ }^{5}$, Verena Kalter ${ }^{1}$, \\ Bola Hanna ${ }^{1}$, Lavinia Arseni ${ }^{1}$, Philipp M. Roessner (DD ${ }^{1}$, Manfred Schmidt ${ }^{2,3}$, Stephan Stilgenbauer ${ }^{6}$, Sascha Dietrich (DD ${ }^{5}$, Peter Lichter (DD ${ }^{1}$, \\ Marc Zapatka (iD ${ }^{1,8}$ and Martina Seiffert (D) $^{1,8}$ 凶
}

(c) The Author(s) 2021

\begin{abstract}
Chronic lymphocytic leukemia (CLL) is a B-cell malignancy mainly occurring at an advanced age with no single major genetic driver. Transgenic expression of TCL1 in B cells leads after a long latency to a CLL-like disease in aged E $\mu$-TCL1 mice suggesting that TCL1 overexpression is not sufficient for full leukemic transformation. In search for secondary genetic events and to elucidate the clonal evolution of CLL, we performed whole exome and B-cell receptor sequencing of longitudinal leukemia samples of E $\mu$-TCL1 mice. We observed a B-cell receptor stereotypy, as described in patients, confirming that CLL is an antigen-driven disease. Deep sequencing showed that leukemia in E $\mu$-TCL1 mice is mostly monoclonal. Rare oligoclonality was associated with inability of tumors to develop disease upon adoptive transfer in mice. In addition, we identified clonal changes and a sequential acquisition of mutations with known relevance in CLL, which highlights the genetic similarities and therefore, suitability of the E $\mu$-TCL1 mouse model for progressive CLL. Among them, a recurrent gain of chromosome 15, where Myc is located, was identified in almost all tumors in E $\mu$ TCL1 mice. Interestingly, amplification of 8q24, the chromosomal region containing MYC in humans, was associated with worse outcome of patients with CLL.
\end{abstract}

Leukemia (2022) 36:464-475; https://doi.org/10.1038/s41375-021-01381-4

\section{INTRODUCTION}

Cellular heterogeneity and clonal evolution of tumors are of major interest in the era of targeted therapies, as these likely impact differently on specific cancer clones. During treatment, some tumor clones get reduced, but inadvertently drugs also provide potent selective pressure for expansion of other clones, a major cause of therapy resistance [1]. Chronic lymphocytic leukemia (CLL) is a malignancy of mature $B$ cells in which genetic driver lesions and their relationship to clonal evolution have been identified [2], and an association of clonal evolution with treatment relapse and drug resistance has been described [3].

$E \mu-T C L 1$ mice are the most accepted and widely used mouse model of CLL for studying disease biology and for preclinical drug testing. This mouse model line was established by exogenous expression of the human TCL1 gene under the control of the immunoglobulin heavy chain variable region (IGHV) promoter and IGH (E $\mu)$ enhancer [4]. Starting from 6 months of age, these mice develop a CLL-like disease characterized by an accumulation of
$\mathrm{CD}^{+} \mathrm{B}$ cells in blood and lymphoid organs, affecting almost $100 \%$ of the animals. Usually only at an age of more than 12 months, mirroring the median age of 70 for CLL diagnosis in humans [5], these mice develop end-stage disease with splenomegaly and very high leukemic cell counts in blood. The expanded leukemic cells exhibit clonal immunoglobulin rearrangements and B-cell receptor (BCR) sequences without IGHV hypermutations, but stereotyped heavy-chain complementarity-determining region 3 (HCDR3) regions as similarly observed in about $30 \%$ of patients with CLL [6]. Although the TCL1 gene is variably expressed in CLL patients, higher expression is associated with unmutated IGHV status, a characteristic that correlates with more aggressive disease and shorter lymphocyte doubling time [7, 8]. Accordingly, the $\mathrm{E} \mu-T C L 1$ mouse model is widely accepted as a model of aggressive CLL and has been extensively used to study the role of mouse orthologs of various genetic players in CLL such as BTK, $P R K C B$, and TP53 [6, 9-11]. The long latency of leukemia development in this model suggests that TCL1 overexpression

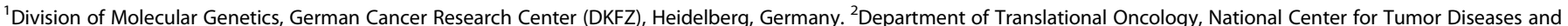

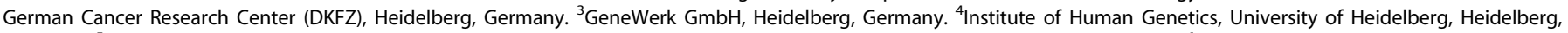

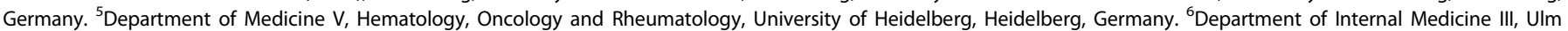

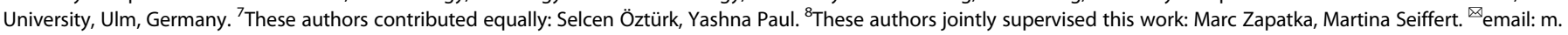
seiffert@dkfz.de 
acts as a predisposing factor or initial hit for premalignant transformation, yet other genetic or microenvironmental aberrations appear to be required for full leukemic transformation [12]. Consequently, this raises the possibility that the gain of genomic aberrations plays an active role in disease development in these mice. However, this has not been investigated intensively so far.

In this study, we aimed to identify the genomic aberrations, which might contribute to the leukemia development in the $\mathrm{E} \mu$ TCL1 mouse model, as well as study the clonal evolution using serial transplantation of TCL1 leukemia. To achieve this, we performed whole exome sequencing (WES) as well as targeted sequencing of the complementarity-determining region 3 of the $B C R$ locus of malignant $B$ cells isolated from leukemic E $\mu-T C L 1$ mice and from animals after serial transplantation of leukemia cells in syngeneic wild-type (WT) mice. We observed that about half of the tumors were monoclonal, and oligoclonal tumors consisted of one major BCR clone. In addition, an increased mutational load, partly accompanied by BCR changes was observed upon transplantation of tumors. Most strikingly, all tumors but one showed a gain in chromosome 15, and therefore Myc, which we propose to be the main second hit for tumor formation in this mouse model.

\section{RESULTS}

To characterize the genetic complexity and evolution of malignant $B$ cells in the E $\mu$-TCL1 mouse model of CLL, we performed WES of purified splenic B cells and germline controls of eight $E \mu-T C L 1$ mice manifesting CLL-like symptoms (primary tumor), as well as four mice, which were serially transplanted with malignant B cells of four different primary tumors (Fig. 1a). Average sequencing coverage at targeted regions for eight tumor samples (primary vs. transplanted) from our cohort was $\sim 180 \times$, except for the four lowly sequenced primary samples in which the average coverage was 80x (Table S1). We further included a recently published dataset (SRP150049) of WES of TCL1 tumors [13] in the analysis. The workflow utilized for this analysis is outlined in Fig. S1. We detected a mutation load in the range of 0.1-2.0 per Mb, which is in line with the low mutation rate detected in CLL patients, which is typically around 0.8 per $\mathrm{Mb}$ [14].

In both cohorts, serial transplantation of tumors resulted in an increase in mutational load (somatic nucleotide variants (SNVs) and small Indels/Mb in coding regions; Fig. S2). This observation was independent of the sequencing depth at the targeted regions (Fig. 1b). Variant allele frequency distributions of mutations in all primary and transplanted tumors of our study showed that most mutations have a low-allele frequency (5-10\%; Fig. 1c, upper panel), which may imply existence of several clones and subclones that might evolve when subjected to selection pressure after transplantation. Although the total number of mutations are lower in the SRP150049 dataset, interestingly, allele frequencies were mostly higher than in samples of our study (Fig. 1c, lower panel). Although penetrance of leukemia development in $\mathrm{E} \mu-T C L 1$ mice is near $100 \%$, the course of disease is quite heterogeneous. Therefore, adoptive transfer (AT) of malignant B cells in syngeneic WT mice is frequently used to create cohorts of mice with a more homogenous disease course, which is especially important for preclinical drug testing. Even though most tumors engraft in mice when the genetic background of the recipient and the donor matches, still some tumors are rejected upon transplantation [15]. Furthermore, transfer of one primary TCL1 tumor in several ageand sex-matched recipient mice results frequently in individual differences in tumor development, making analysis of treatment effects challenging in this model (unpublished observations and Table S2). We monitored disease development after transplantation of 14 different primary TCL1 tumors into 4-14 recipient mice each by regular blood collection and analyses (Table S2). As we observed different degrees of heterogeneity in engraftment and leukemia development in the transplanted mice, we analyzed the $B C R$ sequences of these tumors by RACE-PCR to elucidate their clonal composition in depth (Tables 1 and S3). Tumors with several subclones at a considerable percentage showed a heterogeneous engraftment pattern (e.g., E $\mu-T C L 1$ 647) or did not engraft at all (e.g., E $\mu$-TCL1 684) (Tables 1 and S2). Interestingly, some aggressive tumors growing in a very short time became monoclonal in the recipient mice by loss of previously existing minor subclones (e.g., E $\mu$-TCL1 1000; Tables 2 and S2).

In addition, BCR sequences from WES data of mouse tumors were used as input for MiXCR analyses for identifying tumorspecific V(D)J clonotypes. Six samples analyzed by both RACE-PCR and WES and resulting in the same $V(D) J$ sequences, demonstrated that WES data can be also used to reliably predict $V(D) J$ clonotypes (Table S3). However, as the read counts for the BCR genomic locus were low in WES, quantification was more reliable by RACE-PCR. Eight out of 22 sequenced primary tumors had monoclonal BCRs $(\geq 99.5 \%)$. Seven had a dominant clone comprising more than $95 \%$ of the tumor. Only 4 out of 22 tumors comprised of several clones with a prevalence of more than $10 \%$ of the tumor. We detected stereotyped BCRs, which use the variable genes Ighv1-55, Ighv11-2, and Ighv12-3 as the most frequent clonotypes of the malignant $B$ cells (Table 1 ), which is in line with previous reports $[6,16]$. Analysis of the BCR sequences of sequential tumor samples showed that the main BCR clone is conserved upon AT of tumors (Fig. 2 and Tables 2, S3), except for 1 sample, where a clone with the same $V$ and $J$ chain, but with a new $D$ chain emerged in one of the three recipients of the transplant (Fig. 2, TCL1 595). No reads were detected for the emerging new clone in the primary tumor (Table S3).

Next, we investigated the clonal evolution dynamics of these serially transplanted tumors with respect to somatic mutations as well as their BCR sequences. To identify evolving SNV clones, we used an approach to track dynamics of SNV clusters, i.e., groups of SNVs having similar cancer cell fractions at a time point rather than tracking clonal changes only by certain driver genes. For this, filtered SNVs (Table S4: in-house samples and Table S5: SRP150049 samples), their allele frequencies and copy number states as estimated using CNVkit, were used as input for PyClone that evaluated clusters of putative somatic clones and changes in the fractions of their cellular prevalence as the disease progressed in primary to transplanted tumors (Table S6) [17, 18]. Also, changes in proportions of BCR clonotypes from primary to transplanted tumors were noted. On tracking the dynamics of BCR clonotypes and changes in cellular prevalence of somatic mutations, several patterns of clonal evolution were evident. In the first pattern shown in Fig. 3a, tumors exhibited a change in the proportion of $B C R$ clonotypes in the primary tumor vs. the transplanted tumor, and associated with that are changes in prevalence of SNV-defined subclones upon tumor transplantation. This pattern is indicative of an expanding new major clone that could be driven by acquired novel somatic SNVs in the transplanted tumors. In the second pattern, tumors showed stable clonotype proportions with $B$ cells harboring one major $B C R$, and relatively stable SNV-defined subclones, indicative of a clonally stable disease before and after tumor transplantation without novel somatic SNVs arising (Fig. 3b). Interestingly, as a third pattern, one of the analyzed tumor pairs showed a stable BCR clonotype but major changes in SNV-defined subclones, indicative of a mutating tumor clone (Fig. $3 \mathrm{c}$ ). Mutations associated with each of these patterns are marked in Tables S4 and S5. Overall, these results indicate that different clonal evolution patterns are observed in different tumors of $\mathrm{E} \mu-T C L 1$ mice, which might depend on the varying proliferative capacities of the malignant cells and the presence of specific mutations providing advantages to some clones compared to others.

Furthermore, we examined mutations leading to amino acid changes that are predicted to affect protein function using SIFT 
a)

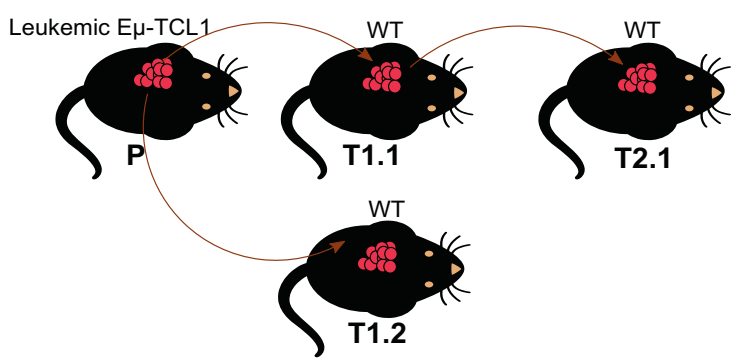

b)

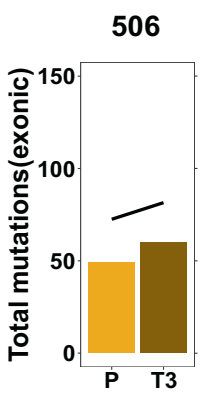

729
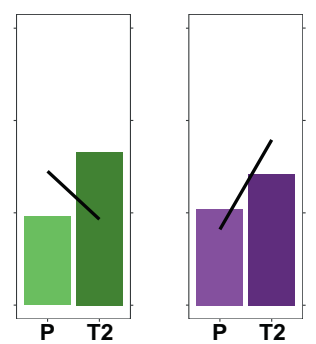

774
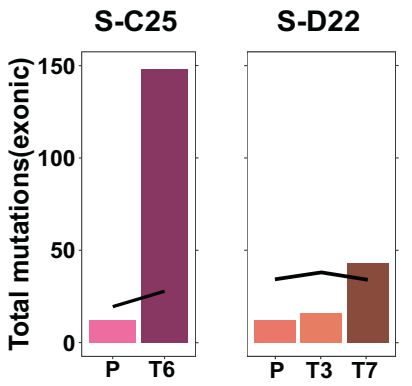

S-E31
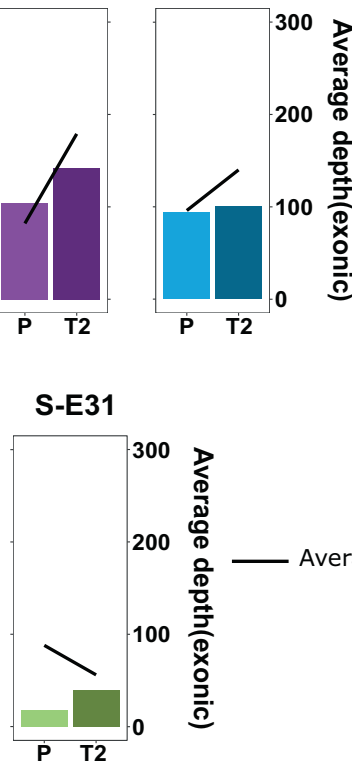

c)
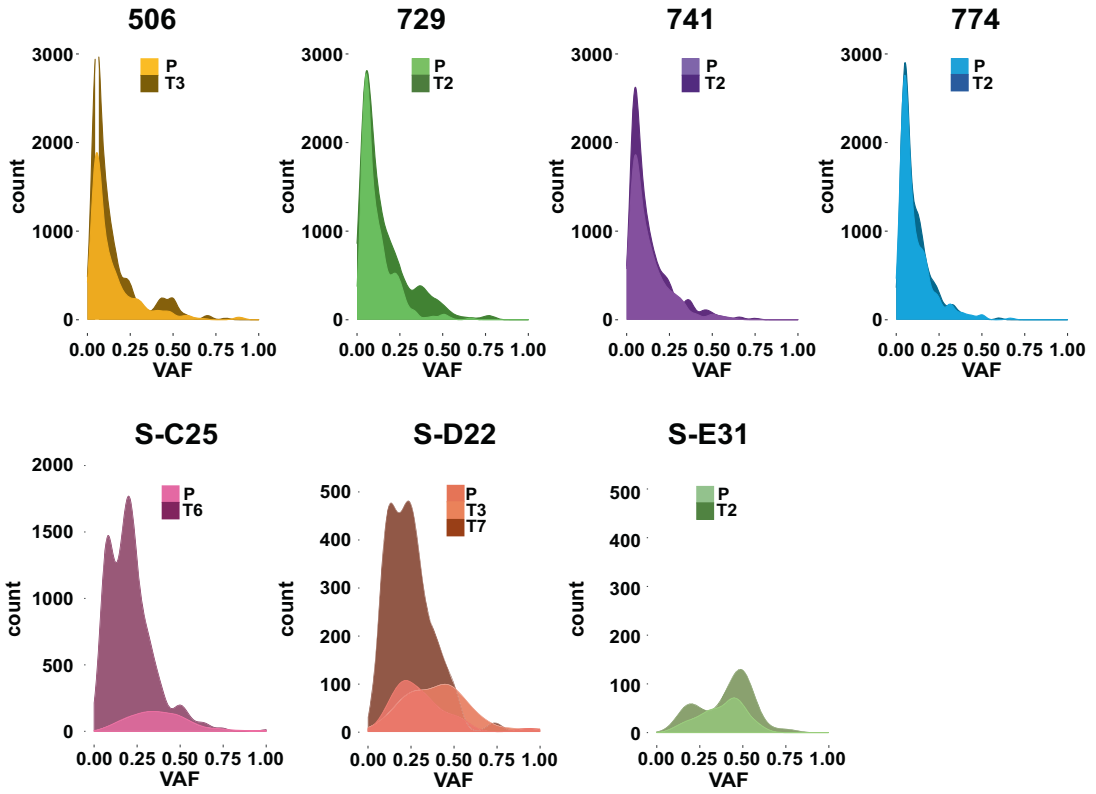

Fig. 1 Exonic mutations in tumors of E $\mu$-TCL1 mice. a Scheme showing the transplantation of tumors isolated from spleens of primary E $\mu$ $T C L 1$ mice $(P)$ to serially transplanted mice (T1, T2 etc). b Total exonic mutations as well as average sequencing depth at the targeted region is depicted for primary E $\mu$-TCL1 tumors (P) and matched serially transplanted tumors (T3: $3 \times$ transplanted, T2: $2 \times$ transplanted, etc), in the upper panel for samples from this study and in the lower panel for samples from SRP150049 cohort (samples denoted by S-). c Variant allele frequency (VAF) distributions of mutations in primary $\mathrm{E} \mu-T C L 1$ tumors and matched serially transplanted tumors are shown, in the upper panel for samples from this study and in the lower panel for samples from SRP150049 cohort. 
Table 1. Ighv gene composition of 22 primary E $\mu$-TCL1 tumors as revealed by targeted sequencing followed by RACE-PCR.

\begin{tabular}{|c|c|c|c|}
\hline ID & Clone_no & $\%$ & Ighv \\
\hline 741 & 1 & 100.0 & Ighv1-26 \\
\hline 661 & 1 & 100.0 & Ighv1-74 \\
\hline 695 & 1 & 100.0 & Ighv1-55 \\
\hline 636 & 1 & 100.0 & Ighv11-2 \\
\hline 813 & 1 & 100.0 & Ighv1-55 \\
\hline 683 & 1 & 99.8 & Ighv11-2 \\
\hline 902 & 1 & 99.8 & Ighv12-3 \\
\hline 7498 & 1 & 99.5 & Ighv11-2 \\
\hline \multirow[t]{2}{*}{774} & 1 & 98.7 & Ighv11-2 \\
\hline & 2 & 1.2 & Ighv1-55 \\
\hline \multirow[t]{2}{*}{850} & 1 & 98.1 & Ighv1-55 \\
\hline & 2 & 1.7 & lghv1-74 \\
\hline \multirow[t]{2}{*}{648} & 1 & 98.0 & Ighv1-55 \\
\hline & 2 & 1.2 & Ighv4-1 \\
\hline \multirow[t]{2}{*}{6029} & 1 & 97.7 & Ighv1-55 \\
\hline & 2 & 2.0 & Ighv2-9-1 \\
\hline \multirow[t]{2}{*}{756} & 1 & 97.6 & Ighv12-3 \\
\hline & 2 & 1.8 & Ighv11-2 \\
\hline \multirow[t]{2}{*}{739} & 1 & 96.8 & Ighv1-55 \\
\hline & 2 & 3.0 & Ighv11-2 \\
\hline
\end{tabular}

\begin{tabular}{|c|r|r|l|}
\hline ID & Clone_no & $\%$ & Ighv \\
\hline 723 & 1 & 96.6 & Ighv12-3 \\
\cline { 2 - 4 } & 2 & 3.0 & Ighv11-2 \\
\hline 595 & 1 & 94.5 & Ighv12-3 \\
\cline { 2 - 4 } & 2 & 4.9 & Ighv1-58 \\
\hline 1000 & 1 & 92.4 & Ighv12-3 \\
\cline { 2 - 4 } & 2 & 7.1 & Ighv5-9-1 \\
\hline 729 & 1 & 87.3 & Ighv1-55 \\
\cline { 2 - 4 } & 2 & 6.9 & Ighv2-3 \\
\cline { 2 - 4 } & 3 & 5.0 & Ighv1-64 \\
\hline 647 & 1 & 87.3 & Ighv1-64 \\
\cline { 2 - 4 } & 2 & 12.7 & Ighv12-3 \\
\hline 684 & 1 & 74.4 & Ighv1-39 \\
\cline { 2 - 4 } & 2 & 14.4 & Ighv5-16 \\
\cline { 2 - 4 } & 3 & 7.1 & Ighv1-11 \\
\cline { 2 - 4 } & 4 & 2.3 & Ighv9-3 \\
\cline { 2 - 4 } & 5 & 0.8 & Ighv11-2 \\
\hline \multirow{3}{*}{506} & 1 & 68.2 & Ighv4-1 \\
\cline { 2 - 4 } & 2 & 31.8 & Ighv12-3 \\
\hline \multirow{3}{*}{909} & 1 & 51.4 & Ighv11-2 \\
\cline { 2 - 4 } & 2 & 27.5 & Ighv12-3 \\
\cline { 2 - 4 } & 3 & 20.3 & Ighv5-17 \\
\cline { 2 - 4 } & & & \\
\hline
\end{tabular}

Recurrent variable genes are colored.

analysis [19]. Using the criteria of an allele frequency of at least $10 \%$ and having a read coverage of the alternative allele of at least 5 and considering only the mutations changing across serial transplantations, we have detected deleterious mutations in the following 15 genes: Speg, Ush2a, Obscn, Kcnk16, Pdia2, Grk2, Spi1, Ptpn3, Sema3a, Raf1, Smg1, Arhgef7, Ikbkb, AW551984, and Tbx18 (Table S4). Most of these mutations were detected only in the serially transplanted tumors, except for $T b \times 18$, for which the allelic fraction of the mutation is $6.9 \%$ in the primary tumor and increases to $50.9 \%$ in the serially transplanted tumor. As Tbx18 has been shown to have a role in proliferation and tumorigenesis, this mutation is likely to provide a growth advantage for the transplanted tumor [20]. Interestingly, we have observed a deleterious mutation for Ush2a in three out of four serially transplanted tumors. As Ush2a mutations have been shown to play a role in several leukemias and lymphomas, it is possible that this deleterious mutation contributes to the more aggressive phenotype of the transplanted tumors [21-23].

We next investigated whether the detected mutations have pathogenic relevance in humans. We identified a total of 509 mutated genes across all our samples that were previously reported as being pathogenic in the COSMIC database v90 (Table S4), and there is a significant overlap with human pathogenic CLL genes in COSMIC ( $p<1^{-5}$, Chi square test). Furthermore, we mapped the identified SNVs to the human CLL gene list $(n=309)$ from the DISEASE database (Fig. 4). Out of 17 genes that mapped to the DISEASE database, 7 have been linked to pathogenesis of human CLL and/or other leukemias (Birc3, Wnt5a, SP140, Atr, Lyn, CD274, and Flt3), and SIFT analysis revealed that the detected mutation in Lyn is likely deleterious (Table S4). These results suggest that disease development in the $\mathrm{E} \mu-\mathrm{TCL} 1$ mouse model is driven by similar pathways as CLL in patients. For example, BIRC3 mutations (mostly nonsense and frameshift variants) were identified in fludarabine-refractory CLL patients, and were also used to define a high-risk CLL group [24]. Several kinds of dysregulation of the Wnt signaling pathway have been reported in leukemias [25]. Further, FLT3 mutations were found in one-third of newly diagnosed acute myeloid leukemia patients, and FLT3 internal tandem duplication was associated with relapse and inferior survival [26]. SP140 was one of the mutations identified in hyperdiploid multiple myeloma samples [27]. However, none of these mutations were recurring across our analyzed samples, and therefore attributed to clonal heterogeneity.

By analyzing the copy number variations in the tumor samples analyzed by WES (Table S7), we observed a deletion in chromosome 12 in almost all samples (Figs. 5a and S3), which is located within the immunoglobulin variable region, and therefore is expected to occur during VDJ recombination in B cells. Interestingly, in 13 out of $15(87 \%)$ primary tumor samples $(7 / 8$ of our samples and 6/7 of SRP150049), a gain of chromosome 15 (chr15) was identified (Figs. 5a and S3). We further detected the same pattern of chr15 gain in the respective transplanted tumors (Fig. S3). We excluded that this was due to a chromosomal 


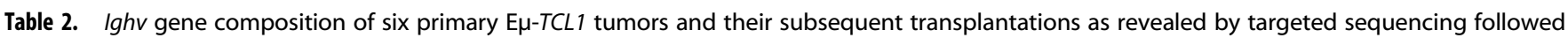
by RACE-PCR.

\begin{tabular}{|l|l|l|l|}
\hline ID & Clone_no & $\%$ & Ighv \\
\hline 774 & 1 & 98.7 & Ighv11-2 \\
\hline & 2 & 1.2 & Ighv1-55 \\
\hline $774-2.1$ & 1 & 99.8 & Ighv11-2 \\
\hline 729 & 1 & 87.3 & Ighv1-55 \\
\cline { 2 - 4 } & 2 & 6.9 & Ighv2-3 \\
\cline { 2 - 4 } & 3 & 5.0 & Ighv1-64 \\
\hline $729-1.1$ & 1 & 97.2 & Ighv1-55 \\
\cline { 2 - 4 } & 2 & 1.7 & Ighv2-3 \\
\cline { 2 - 4 } & 3 & 1.1 & Ighv12-3 \\
\hline $729-2.1$ & 1 & 58.7 & Ighv12-3 \\
\cline { 2 - 4 } & 2 & 37.0 & Ighv1-55 \\
\cline { 2 - 4 } & 3 & 4.3 & Ighv2-3 \\
\hline $729-1.2$ & 1 & 89.9 & Ighv1-55 \\
\cline { 2 - 4 } & 2 & 6.8 & Ighv12-3 \\
\cline { 2 - 4 } & 3 & 3.2 & Ighv2-3 \\
\hline \multirow{5}{*}{$729-1.3$} & 1 & 88.5 & Ighv1-55 \\
\cline { 2 - 4 } & 2 & 10.2 & Ighv2-3 \\
\hline
\end{tabular}

\begin{tabular}{|l|l|l|l|}
\hline ID & Clone_no & $\%$ & Ighv \\
\hline 595 & 1 & 94.5 & Ighv12-3 \\
\cline { 2 - 4 } & 2 & 4.9 & Ighv1-58 \\
\hline $595-1.1$ & 1 & 99.3 & Ighv12-3 \\
\hline $595-1.2$ & 1 & 99.0 & Ighv12-3 \\
\hline $595-1.3$ & 1 & 91.7 & Ighv12-3 \\
\cline { 2 - 4 } & 2 & 5.4 & Ighv11-2 \\
\hline \multirow{2}{*}{1000} & 1 & 92.4 & Ighv12-3 \\
\cline { 2 - 4 } & 2 & 7.1 & Ighv5-9-1 \\
\hline $1000-1.1$ & 1 & 99.8 & Ighv12-3 \\
\hline $1000-1.2$ & 1 & 99.8 & Ighv12-3 \\
\hline $1000-1.3$ & 1 & 99.9 & Ighv12-3 \\
\hline 741 & 1 & 100.0 & Ighv1-26 \\
\hline $741-2.1$ & 1 & 100.0 & Ighv1-26 \\
\hline 506 & 1 & 68.2 & Ighv4-1 \\
\cline { 2 - 4 } & 2 & 31.8 & Ighv12-3 \\
\hline $506-3.1$ & 1 & 71.6 & Ighv4-1 \\
\cline { 2 - 4 } & 2 & 28.4 & Ighv12-3 \\
\hline
\end{tabular}

Recurrent variable genes are colored. Primary tumors are listed first, followed by respective serially transplanted tumors (e.g., 774-2.1: tumor 774, transplanted 2 times, number 1 out of $\mathrm{x}$ ).

abnormality of the mouse line, as the germline samples did not show this gain. Interestingly, Myc oncogene is located on chr15 within the gained region in mice. To confirm the gain of $M y c$ in malignant cells of E $\mu$-TCL1 mice, we performed interphase FISH analysis of splenocytes from 14 leukemic $E \mu-T C L 1$ mice with primary disease, 3 non-leukemic, 5 -week-old $\mathrm{E} \mu$-TCL 1 mice, as well as 5 WT littermate mice from the E $\mu$-TCL1 breeding (Fig. $5 \mathrm{~b}$ and Table S8). In addition to a Myc-specific FISH probe, we used a chromosome 16 probe to exclude polyploidy of the tumor cells. Minor tetraploidy was detected in $10 / 17$ TCL1 samples $(0.51 \%$ in 9 samples and $6.7 \%$ in 1 sample) and those cells were excluded from the analysis. Twelve out of 14 primary tumor samples showed trisomy of $M y c$ in almost all tumor cells (Fig. 5b; exception $\# 684$ and \#648 with $<10 \%$ of cells with Myc gain). Interestingly, both mice with early or late stage (reflected by the tumor load) of the primary disease showed Myc gain (Fig. 5b and Table S8), suggesting that $M y c$ gain is an early event in malignant transformation in this model. In 11 of these tumor samples, tetrasomy of the Myc locus was also detected, although at a much lower frequency $(0.5-5 \%$ of analyzed cells) (Table S8). We have not detected more than four copies of Myc in any of the samples. By analyzing healthy WT and non-leukemic E $\mu$-TCL1 mice, a very low frequency of trisomy 15 was detected in one out of three nonleukemic E $\mu$-TCL1 samples (3\% of cells) as well as two out of five WT samples (3\% of cells) (Table S8). Remarkably, one tumor sample (\#684) that showed Myc gain only in 4\% of the cells (Fig. 5b) did not engraft in any of the transplanted mice (0 out of 10 mice; Table S2), suggesting that gain of $M y c$ is necessary for tumor cell engraftment. Further, another tumor sample (\#648) with a very low percentage of Myc gain (Fig. 5b) engrafted only in two out of four transplanted mice (Table S2), and in the engrafted tumors (\#648 T1.1 and \#648 T1.2), trisomy of Myc, however, was detected in all CLL cells (Fig. 5b; Table S8).

In order to test if the gain of the Myc locus also leads to enhanced expression of c-MYC protein, we performed intracellular flow cytometry. Normal B cells from WT mice did not express any detectable levels of c-MYC (Fig. 5c). On the other hand, CLL cells from $\mathrm{E} \mu-T C L 1$ mice showed varying levels of c-MYC expression, with some mice expressing it at a similar level as B cells from $E \mu-$ Myc mice (Fig. 5c), which harbor a B-cell-specific transgenic expression of Myc via the IGVH promoter and $\mathrm{E} \mu$ enhancer and develop a very aggressive lymphoma $[28,29]$. To compare the c-MYC expression in normal B cells and CLL cells from the same mice, we used three mice adoptively transferred with E $\mu-T C L 1$ cells, where the normal B cells originate from the recipient WT mice. In these mice, we observed that c-MYC expression was specific to CLL cells and almost undetectable in normal B cells (Fig. 5d).

Dysregulation of MYC is essential in the pathogenesis of a number of B-cell lymphomas [30]. Besides diffuse large B-cell lymphoma and Burkitt lymphoma, MYC expression has been linked to Richter's syndrome, which is the transformation of CLL into a more aggressive B-cell lymphoma. In a cohort of $134 \mathrm{CLL}$ patients, an amplification of chromosome 8q24, encompassing the MYC locus in humans, was detected in six samples. Although found rarely in CLL patients, this amplification caused a disadvantage in survival as well as shortened the time to next treatment compared to the patients without this amplification (Fig. 6a). As almost all patients with $8 \mathrm{q} 24$ amplification harbored an unmutated IGHV locus (5/6, for one patient unknown), which is associated with shorter survival, we also compared overall survival and time to first treatment only within the cases with unmutated 
TCL1 1000

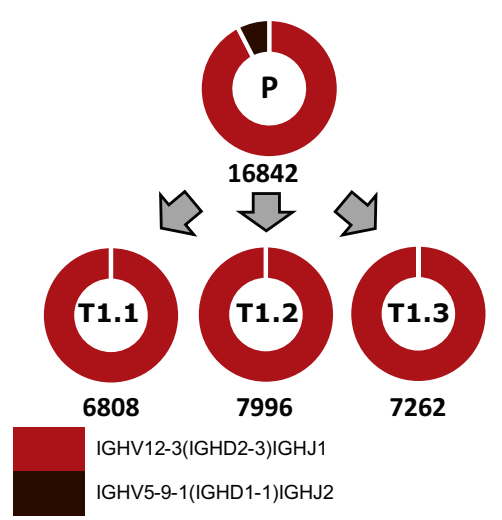

TCL1 729

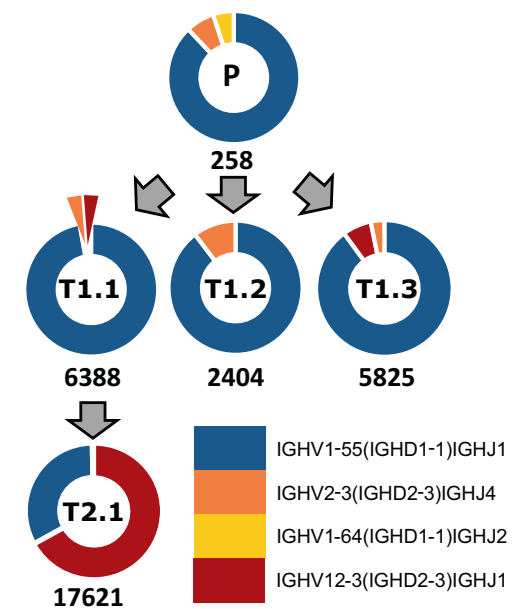

TCL1 595

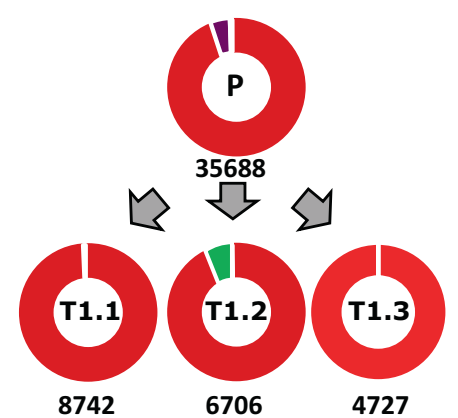

I

IGHV12-3(IGHD2-7,IGHD2-8,IGHD5-8)IGHJ1

IGHV12-3(IGHD4-1)|GHJ1

IGHV11-2,IGHV11-1()|GHJ1

IGHV1-58(IGHD1-1,IGHD2-3)|GHJ2

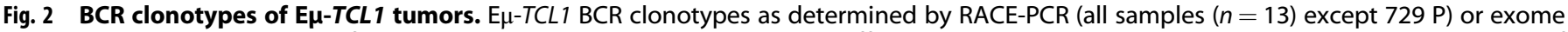
sequencing (729 P) and identified using MiXCR. Each color represents a different V(D)J rearrangement, which is listed under each set of samples. Total number of reads in each sample is indicated below the donut plot and the sample number is indicated in the donut plot $(P$ primary, T transfer).

IGHV. Although 8q24 amplification did not affect survival within this patient group, it still led to a worse outcome with respect to time to first treatment (Fig. 6b). These results suggest MYC as an oncogenic driver of progressive CLL also in patients.

\section{DISCUSSION}

$\mathrm{CLL}$ is a B-cell malignancy driven by antigenic stimulation of the $B C R$, as well as genetic aberrations affecting different cellular pathways, including RNA processing, DNA damage and cell cycle control, chromatin modifications, Notch and Wnt signaling, and inflammatory pathways [2]. Clonality analysis of WES data of CLL patients allowed the identification of temporal relationships between driver events, and a direct comparison between matched pretreatment and relapse samples demonstrated highly frequent clonal evolution in CLL [2]. So far, only limited data of genetic aberrations in the $E \mu-T C L 1$ mouse model of CLL and their temporal behavior during disease progression exist [13].

Similar to human CLL, nonoverlapping low-allele frequency SNVs $(<5 \%)$ were identified in primary and serially transplanted tumor samples of the E $\mu-T C L 1$ mouse model using WES. Among them, we detected SNVs in genes that have been shown to be of relevance in the pathogenesis of human CLL and/or other leukemias. The most prominent one was Birc3, which belongs to the recurrently mutated genes in CLL patients and was found to be associated with increased risk of CLL progression [31, 32]. Another mutated gene, Wnt5a, is a member of the Wnt signaling pathway and was previously shown to bind to ROR1 and thereby to contribute to migration and proliferation of CLL cells [33, 34]. A genetic polymorphism in the gene SP140 has been linked to an increased risk to develop CLL [35], making the identified SP140 mutation of interest. Mutations in the genes CD274 (coding for PDL1) and Lyn are of interest, as the importance of these genes in CLL development was shown both in patients and in the E $\mu-T C L 1$ mouse model [36-39]. Other genes of interest are Flt3 and Atr, which were shown to be upregulated and to have a pathological role in CLL and other leukemias [40-43]. Future follow-up work will be necessary to explore the relevance and underlying mechanism of these or other mutated genes for leukemia development in the $\mathrm{E} \mu-T C L 1$ mouse model, and to estimate the usefulness of TCL1 tumors harboring these mutations as preclinical models for CLL.

As $30 \%$ of CLL patients express quasi-identical BCRs, the socalled "stereotyped" receptors, the existence of common antigenic determinants as drivers of disease was suggested [44]. Both autoantigens arising upon apoptosis or oxidation-specific epitopes, and exogenous microbial antigens were identified as epitopes for these stereotyped BCRs. Of clinical importance, subsets of CLL patients with restricted BCRs have been identified and associated with clinical outcome [44]. Whereas stereotyped 
a)
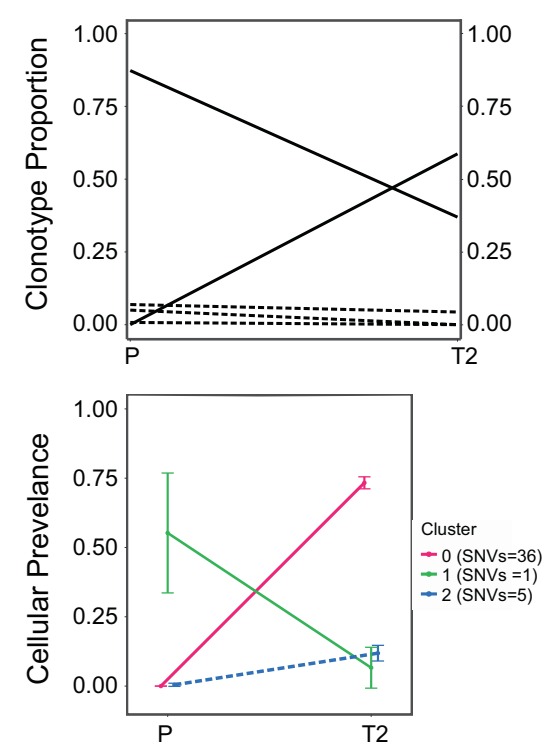

b)
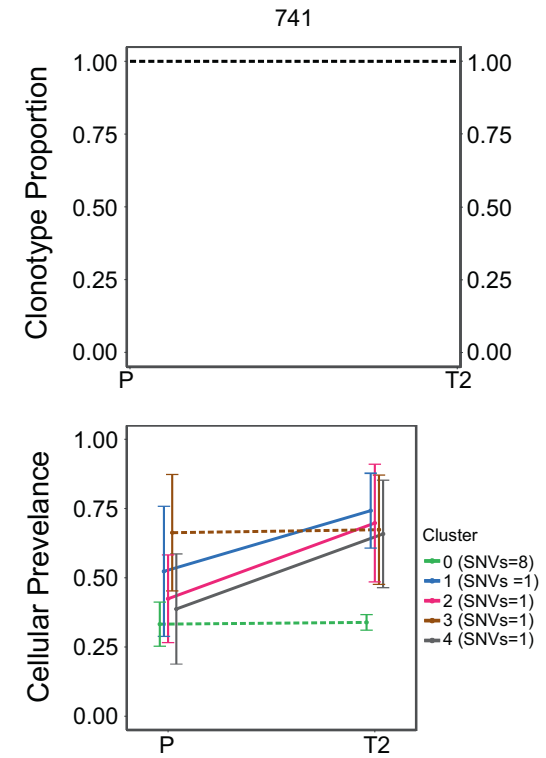

c)

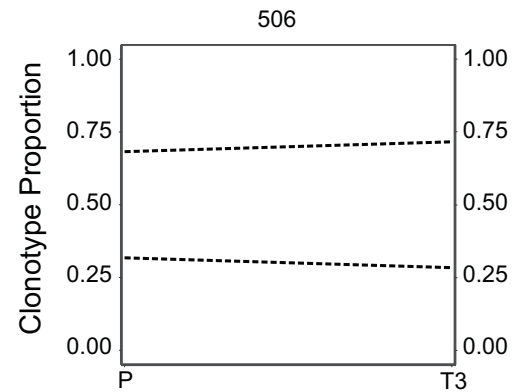

S-C25
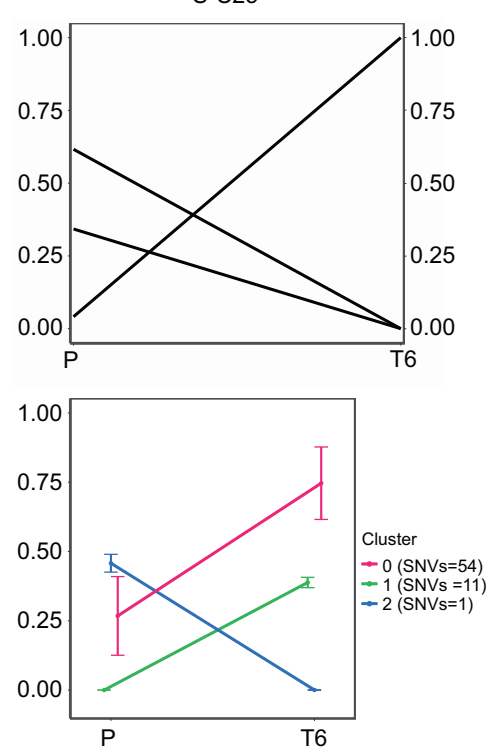

774
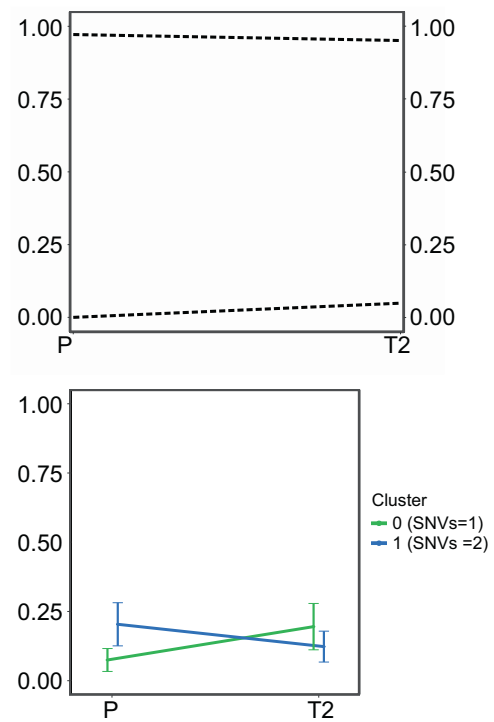

S-E31
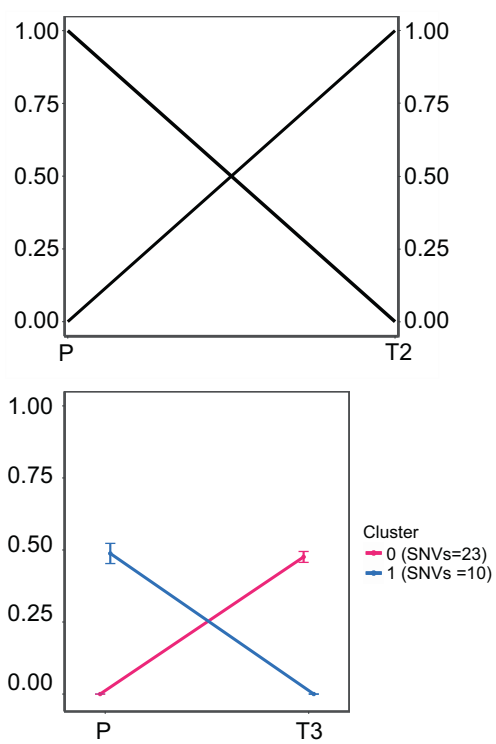
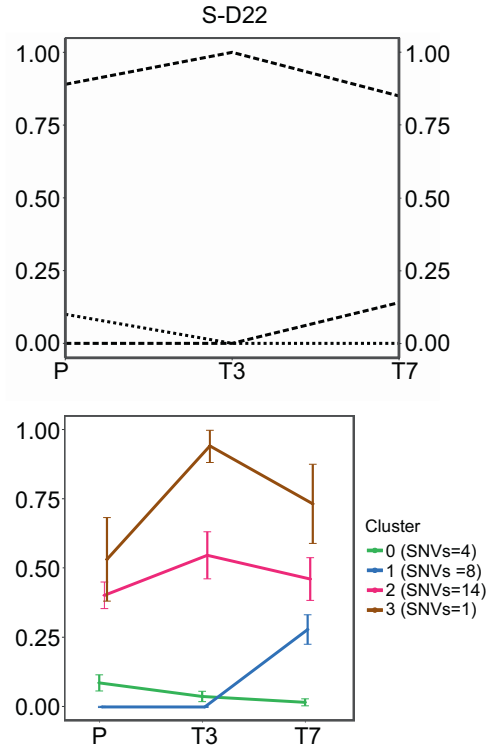

Fig. 3 Clonal evolution of Eu-TCL1 tumors identified by changes in BCR clonotypes and as clusters of somatic variants showing similar allele frequency changes. Three types of clonal evolution patterns (a-c), attributed to changes in proportion of different BCR clonotypes (upper panels) and cellular prevalence of somatic mutation clusters (lower panels) between primary and serially transplanted tumors ( $P$ primary $(n=4), T$ transfer $(n=4))$ are described. SNV cluster is a group of high confidence SNVs with similar allele frequencies at a time point. Changes from primary to transplanted tumors are denoted by solid lines. Changes occurring at $<10 \%$ between primary and transplanted tumors are marked by a dotted line. Samples from SRP150049 $(n=6)$ cohort are denoted by "S-" plus number of sample. 


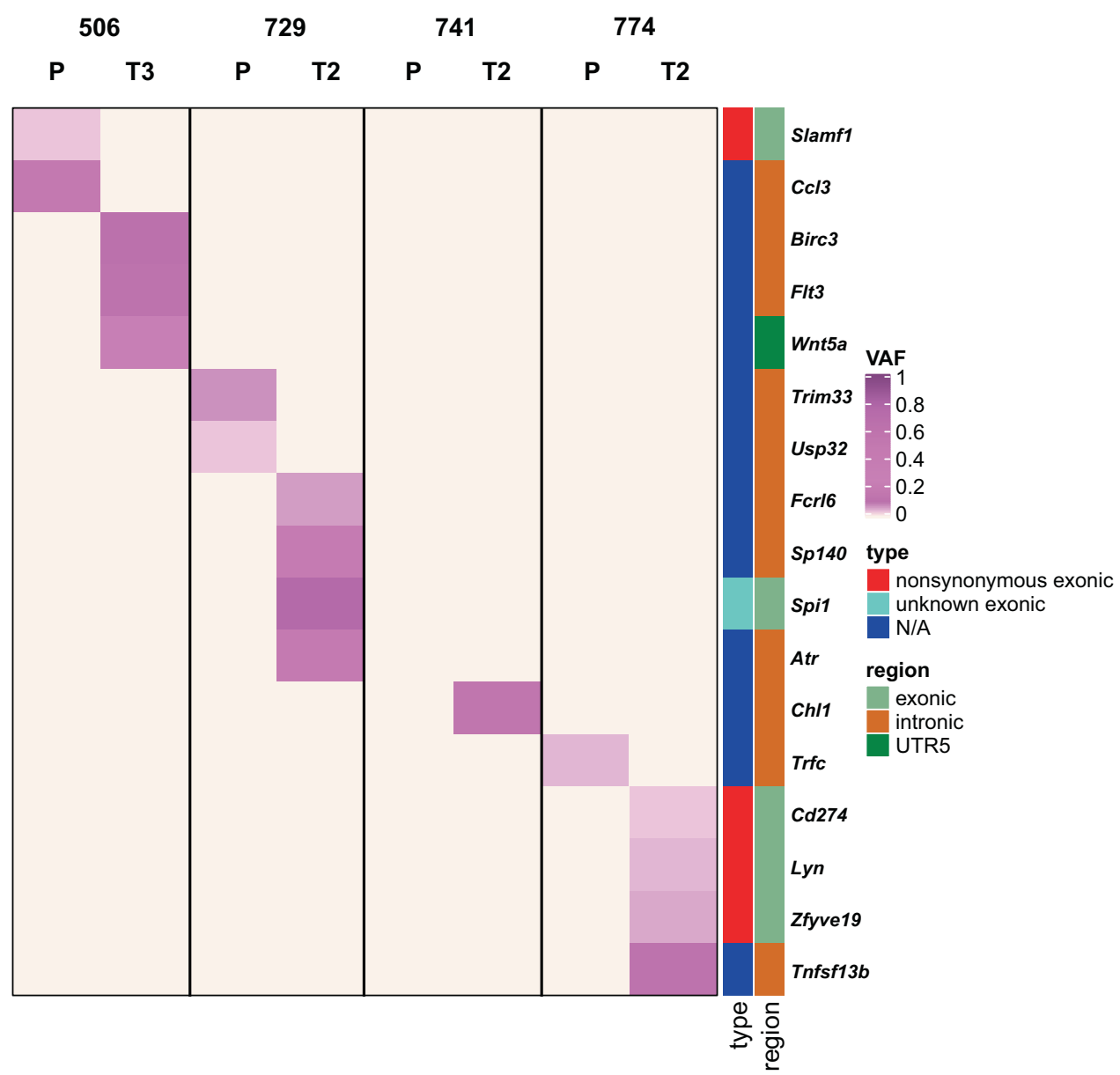

Fig. 4 SNVs mapping to human CLL gene list from DISEASE database. Heatmap displaying variant allele frequencies (VAF) of 17 of the identified SNVs that map to the human CLL gene list $(n=309)$ from the DISEASE database at: https://diseases.jensenlab.org/. Types and regions of SNVs are displayed on the right of the heatmap. Samples of four paired tumors are depicted: P primary, T transfer, N/A not applicable.

subsets \#2 and \#8 using the variable genes IGHV3-21 and IGHV439 , respectively, are linked to poor prognosis, patients of stereotyped subset \#4 using the immunoglobulin genes IGHV434 and IGKV2-30 develop indolent disease [45]. In addition, CLLspecific HCDR3 regions of the BCR were shown to harbor antigenindependent cell-autonomous signaling, which is dependent on an internal epitope of the BCR [46]. The characteristics of BCRs expressed by leukemic $B$ cells of the $E \mu-T C L 1$ mouse model are very similar to what is known in patients, with stereotyped BCRs reactive for microbial or autoantigens, the main one being phosphatidylcholine (PtC), identified as drivers of leukemia development [6]. Further, selection for PtC-reactive B cells was shown to increase the aggressiveness of the leukemia in the $\mathrm{E} \mu$ TCL1 mouse model [16]. This is in line with our findings that identified the PtC-reactive, stereotyped BCRs using the variable genes Ighv11-2 and Ighv12-3 as the most frequent clonotypes of the malignant B cells, together with Ighv1-55. Autoreactive $\mathrm{CD}^{+} \mathrm{B}$ cells with restricted BCRs were shown to be the origin of CLL development in aging mice [47], in which chronic stimulation by autoantigens causing persistent inflammation adds to leukemia progression. This confirms that CLL development in the $\mathrm{E} \mu-T C L 1$ mouse model is driven by antigenic stimulation of the BCR.

Even though CLL is defined as a disease of monoclonal B cells having a unique IGH gene rearrangement, with increasing sequencing sensitivity a considerable fraction of cases with more than one clonotype was detected [48-50]. Two productive IGH rearrangements were discussed to arise in a single CLL cell, which might not follow the rule of allelic exclusion allowing only one productive IGH rearrangement. However, single-cell sequencing showed that allelic exclusion was generally maintained in $C L L$, and multiple productive $I G H$ rearrangements are rather derived from distinct/unrelated clones in selected cases [48]. Bi- or multiclonality in CLL was shown to comprise of either a minor and a major, or equally sized clones, which persisted in patients over time and treatment. Even though the number of analyzed cases is small, multiclonality seemed to be more abundant in CLL cases with mutated IGHV genes, which is the group of patients with less aggressive disease. This is in line with our findings in the $\mathrm{E} \mu-T C L 1$ mouse model, in which multiclonality is rare and associated with an inferior engraftment rate of leukemic cells in WT mice representing a feature of lower aggressiveness. A previous study compared clonality of malignant B cells in the $\mathrm{E} \mu-T C L 1$ model at 4 and 8 months of age and detected several clonotypes at the earlier time point, whereas one major BCR rearrangement was observed in 8-month-old mice suggesting monoclonal expansion of CLL cells during progressive disease [51].

By combining patterns of BCR dynamics and associated SNVdefined subclones, we investigated tumor heterogeneity and evolution in serially transplanted tumors of the E $\mu-T C L 1$ mouse model. Three patterns of evolving SNV-defined subclones and BCR clonotypes emerged from primary to transplanted tumors. In the first pattern, both BCR clonotypes as well as somatic variants were displaced by novel clones after serial transplantation of the tumors. In the second pattern, the same BCR clonotypes and SNV- 
a)

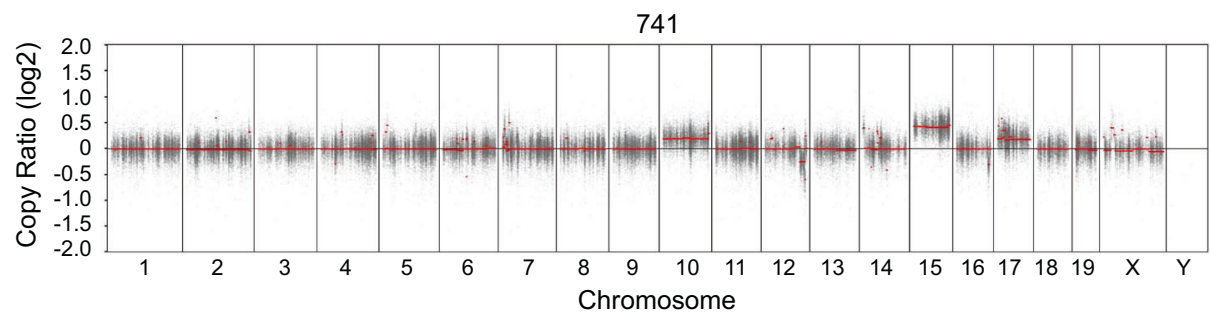

b)

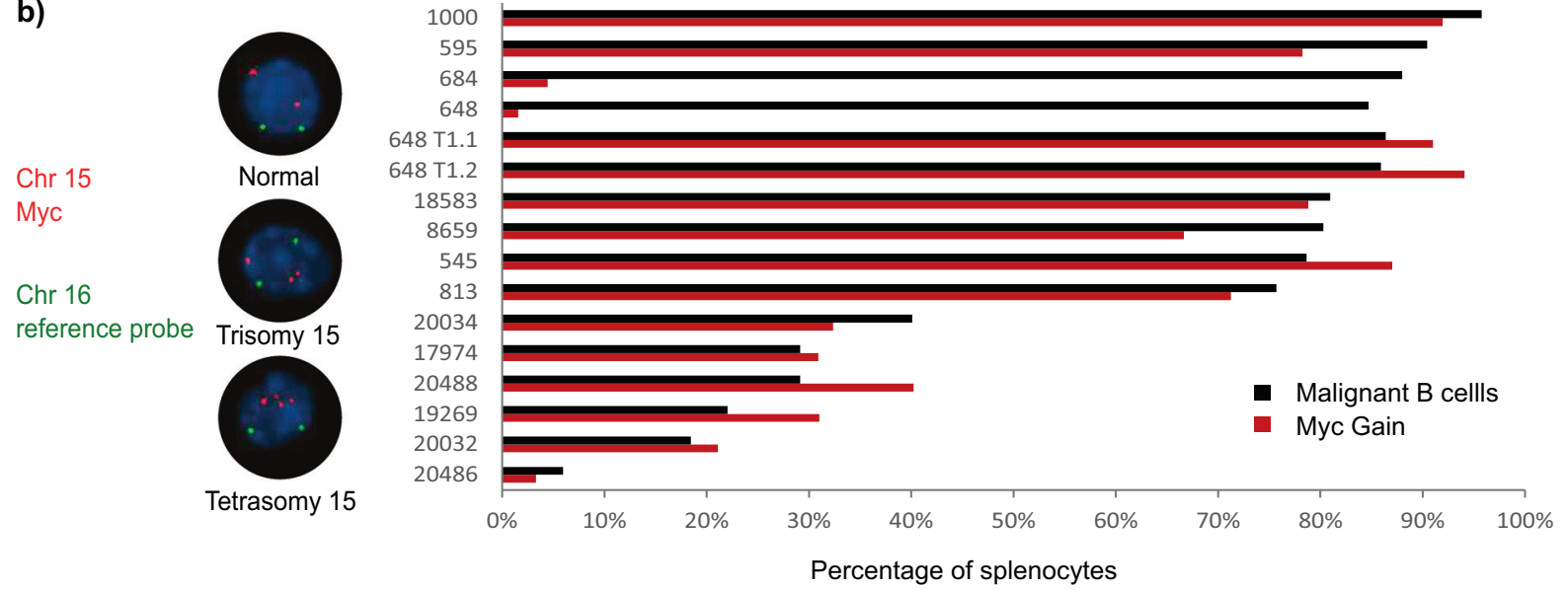

c)
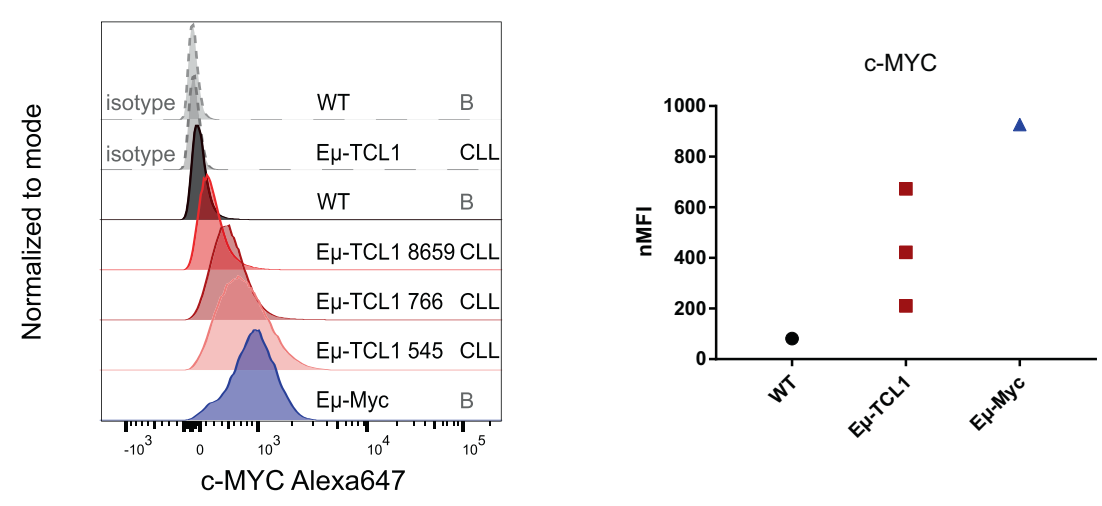

d)

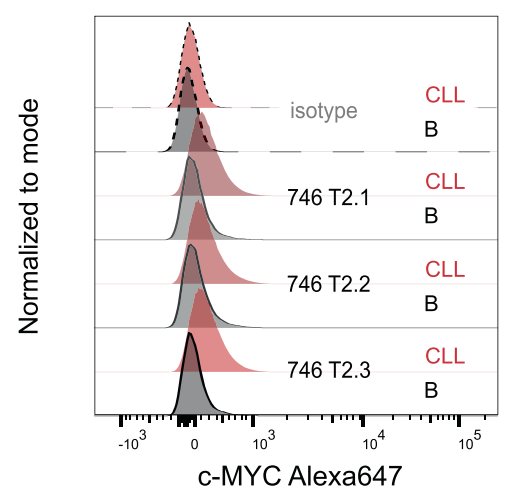

C-MYC

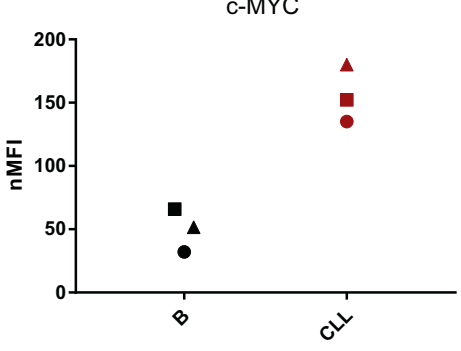

Fig. 5 Gain of Myc in Eu-TCL1 tumors. a CNV plot of one exemplary sample (741) showing gain of Chromosome $15 . \mathbf{b}$ FISH analysis of splenocytes from 14 leukemic Eu-TCL1 mice for Chromosome 15 (Myc region) and Chromosome 16 as a control. Percentage of cells with gain of Myc and percentage of tumor cells identified as CD19+CD5 $5^{+}$are compared in the graph on the right. c Expression of c-MYC in CLL cells from three different leukemic E $\mu$-TCL1 mice, as well as B cells from a WT mouse and an E $\mu-M y c$ mouse, analyzed by flow cytometry. Dashed lines show the isotype control samples. d Expression of c-MYC in CLL cells $\left(C D 19^{+} C D 5^{+}\right)$and conventional B cells $\left(C D 19^{+} \mathrm{CD} 5^{-}\right)$from three different leukemic mice after adoptive transfer, analyzed by flow cytometry. Dashed lines show the isotype control samples. 
a)

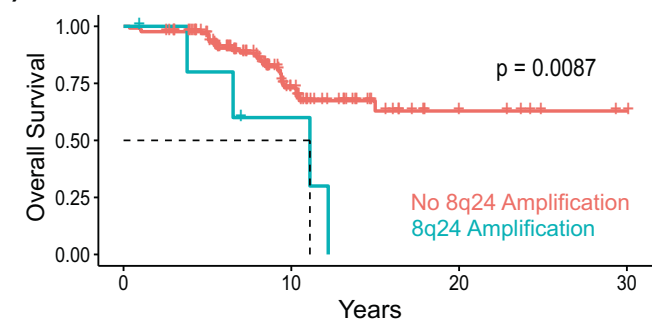

b)

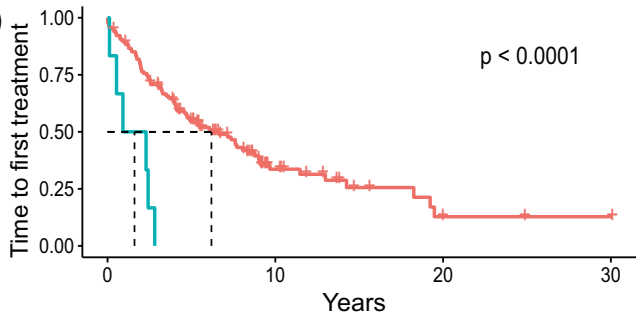

c)

IGHV-U Patients only

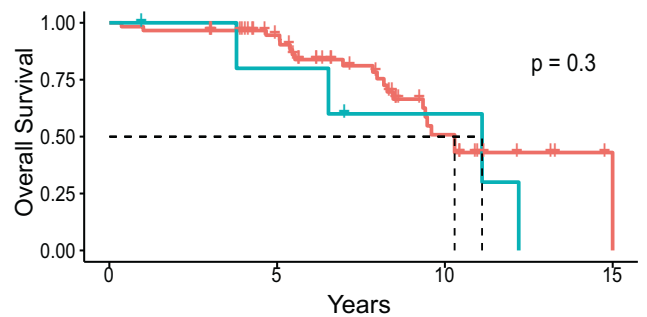

d)

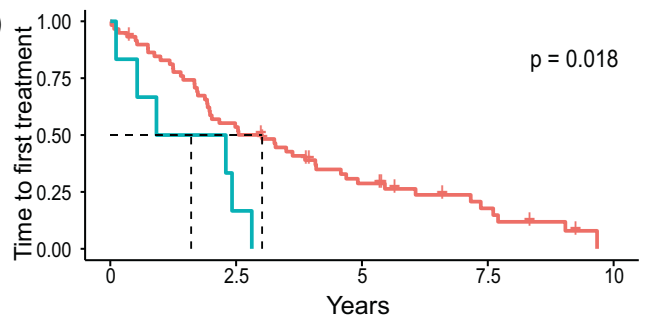

Fig. 6 8q24 amplification in CLL patients. a Overall survival and $\mathbf{b}$ time to treatment analysis of CLL patients with $(n=6)$ or without $(n=128)$ 8 q24 amplification (blue and red line, respectively). c Overall survival and $\mathbf{d}$ time to treatment analysis within patients with unmutated IGHV genes with $(n=5)$ or without $(n=60) 8 q 24$ amplification.

defined clones remained stable at the primary and transplanted time points. The third pattern showed tumors in which the BCR clonotypes remained constant but genetic changes were observed by shifts in SNV-defined clones. The variation in clonal evolution likely depends on the potency of the BCR clones as well as the accumulation of somatic variants and thereby affected genes. The dynamic loss and gain of BCR clonotypes as well as SNV-defined subclones could be indicative of differences in the selection pressure mediated by the tumor microenvironment, including the strength of antitumor immune responses during the course of CLL. Clonal evolution has been shown to be heterogeneous also in patients with CLL and mainly driven by treatment [2]. However, also in untreated CLL, dynamic changes in the disease course of CLL were shaped by the genetic events that were already present in the early slow-growing stages [52]. Especially, subclones with aberrations of known CLL driver genes were shown to harbor a growth advantage over other clones and to display accelerated growth.

Among the well-recognized cancer drivers, MYC appeared to be affected by several recurrent genetic aberrations in CLL[2]. MYC activity has been mainly associated with aggressive, high grade B-cell malignancies [30], and mice with overexpression of Myc in B

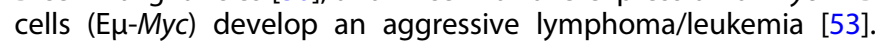
Although it is rare, an amplification of $8 \mathrm{q} 24$, the genomic locus of Myc in humans, has been associated with relapsed/refractory CLL cases previously treated with chemo(immuno)therapy [54]. Furthermore, $8 q 24 / M Y C$ gain is often acquired during the course of disease in CLL and not found in the early stages of the disease. If presented in a complex karyotype, it is frequently associated with Richter's transformation, refractoriness to therapy and an aggressive clinical course [55]. This is in line with our data that clearly show a shorter overall survival of CLL patients harboring an $8 q 24$ amplification. In the $\mathrm{E} \mu-T C L 1$ mouse model, we observed a chromosomal gain of $M y c$ in almost all analyzed tumors which resulted in an aberrant expression of MYC protein in the malignant $B$ cells up to the level of $B$ cells from the E $\mu-M y c$ mouse model. Interestingly, lack of this gain was linked to a low engraftment rate of tumors upon transplantation. Altogether, our data suggest that MYC is a potent driver of CLL development, and the $\mathrm{E} \mu-T C L 1$ mouse line as preclinical model for aggressive, MYCdriven CLL.

\section{METHODS}

A detailed description of methods and analyses can be found in a supplementary file.

\section{Mouse models}

E $\mu$-TCL1 (TCL1) mice on C57BL/6 background were kindly provided by Carlo M. Croce (The Ohio State University, Columbus, Ohio, USA) [4]. Characteristics of all E $\mu$-TCL1 mice used for RACE-PCR and Exome-seq are described in Table S9. Characteristics of all E $\mu$-TCL1 mice used for FISH are described in Table S8. Adoptive transfer (AT) of TCL1 tumors, collection of tissue samples from mice and flow cytometry were performed as previously described [56]. All animal experiments were carried out according to governmental and institutional guidelines and authorized by the local authorities (Regierungspräsidium Karlsruhe, Germany, permit numbers: DKFZ337, G-36/14, G-98/16, and G123/14).

\section{Mouse immunoglobulin repertoire sequencing}

RNA was used for RACE-PCR according to previously described protocols $[57,58]$. List of RACE-PCR oligonucleotides are provided in Table S9.

\section{Sequencing and alignment}

Library preparation for targeted sequencing was performed using SureSelectXT Mouse All Exon kit from Agilent. The samples were subsequently sequenced on HiSeq2000 or HiSeq4000 platforms using 100-bp paired-end reads with 4 samples per lane according to the manufacturer's instructions at the DKFZ Genomics and Proteomics Core Facility.

Data from WES and targeted sequencing can be viewed and downloaded at https://www.ebi.ac.uk/ena/browser/home under the project Id PRJEB42362.

\section{Patients and survival analysis}

The study was approved by the Ethics Committee of the University of Heidelberg. For $136 \mathrm{CLL}$ patients for which WGS or WES has been performed [59], time to first treatment and overall survival were calculated based on clinical follow-up.

\section{REFERENCES}

1. Greaves M, Maley CC. Clonal evolution in cancer. Nature. 2012;481:306-13.

2. Landau DA, Tausch E, Taylor-Weiner AN, Stewart C, Reiter JG, Bahlo J, et al. Mutations driving CLL and their evolution in progression and relapse. Nature. 2015;526:525-30. 
3. Ahn IE, Underbayev C, Albitar A, Herman SEM, Tian X, Maric I, et al. Clonal evolution leading to ibrutinib resistance in chronic lymphocytic leukemia. Blood. 2017;129:1469-79.

4. Bichi R, Shinton SA, Martin ES, Koval A, Calin GA, Cesari R, et al. Human chronic lymphocytic leukemia modeled in mouse by targeted TCL1 expression. Proc Natl Acad Sci U S A. 2002;99:6955-60.

5. Bosch F, Dalla-Favera R. Chronic lymphocytic leukaemia: from genetics to treatment. Nat Rev Clin Oncol. 2019;16:684-701.

6. Yan XJ, Albesiano E, Zanesi N, Yancopoulos S, Sawyer A, Romano E, et al. B cell receptors in TCL1 transgenic mice resemble those of aggressive, treatmentresistant human chronic lymphocytic leukemia. Proc Natl Acad Sci U S A. 2006;103:11713-8.

7. Herling M, Patel KA, Khalili J, Schlette E, Kobayashi R, Medeiros LJ, et al. TCL1 shows a regulated expression pattern in chronic lymphocytic leukemia that correlates with molecular subtypes and proliferative state. Leukemia. 2006;20:280-5.

8. Herling M, Patel KA, Weit N, Lilienthal N, Hallek M, Keating MJ, et al. High TCL1 levels are a marker of B-cell receptor pathway responsiveness and adverse outcome in chronic lymphocytic leukemia. Blood. 2009;114:4675-86.

9. Woyach JA, Bojnik E, Ruppert AS, Stefanovski MR, Goettl VM, Smucker KA, et al. Bruton's tyrosine kinase (BTK) function is important to the development and expansion of chronic lymphocytic leukemia (CLL). Blood. 2014;123:1207-13.

10. Holler C, Pinon JD, Denk U, Heyder C, Hofbauer S, Greil R, et al. PKCbeta is essential for the development of chronic lymphocytic leukemia in the TCL1 transgenic mouse model: validation of PKCbeta as a therapeutic target in chronic lymphocytic leukemia. Blood. 2009;113:2791-4.

11. Liu J, Chen G, Feng L, Zhang W, Pelicano H, Wang F, et al. Loss of p53 and altered miR15-a/16-1 short right arrowMCL-1 pathway in CLL: insights from TCL1-Tg:p53 $(-/-)$ mouse model and primary human leukemia cells. Leukemia. 2014;28:118-28.

12. Simonetti G, Bertilaccio MT, Ghia P, Klein U. Mouse models in the study of chronic lymphocytic leukemia pathogenesis and therapy. Blood. 2014;124:1010-9.

13. Zaborsky N, Gassner FJ, Hopner JP, Schubert M, Hebenstreit D, Stark R, et al. Exome sequencing of the TCL1 mouse model for CLL reveals genetic heterogeneity and dynamics during disease development. Leukemia. 2019;33:957-68.

14. Roos-Weil D, Nguyen-Khac F, Bernard OA. Chronic lymphocytic leukemia: time to go past genomics? Am J Hematol. 2016;91:518-28.

15. Ozturk S, Roessner PM, Schulze-Edinghausen L, Yazdanparast $H$, Kalter V, Lichter $\mathrm{P}$, et al. Rejection of adoptively transferred Emicro-TCL1 chronic lymphocytic leukemia cells in C57BL/6 substrains or knockout mouse lines. Leukemia. 2019;33:1514-39.

16. Chen SS, Batliwalla F, Holodick NE, Yan XJ, Yancopoulos S, Croce CM, et al. Autoantigen can promote progression to a more aggressive TCL1 leukemia by selecting variants with enhanced B-cell receptor signaling. Proc Natl Acad Sci U S A. 2013;110:E1500-7.

17. Roth A, Khattra J, Yap D, Wan A, Laks E, Biele J, et al. PyClone: statistical inference of clonal population structure in cancer. Nat Methods. 2014;11:396-8.

18. Talevich E, Shain AH, Botton T, Bastian BC. CNVkit: genome-wide copy number detection and visualization from targeted DNA sequencing. PLoS Comput Biol. 2016;12:e1004873.

19. $\mathrm{Ng} \mathrm{PC}$, Henikoff S. SIFT: predicting amino acid changes that affect protein function. Nucleic Acids Res. 2003;31:3812-4

20. Chang F, Xing $P$, Song F, Du X, Wang G, Chen $K$, et al. The role of T-box genes in the tumorigenesis and progression of cancer. Oncol Lett. 2016;12:4305-11.

21. Ma X, Edmonson M, Yergeau D, Muzny DM, Hampton OA, Rusch M, et al. Rise and fall of subclones from diagnosis to relapse in pediatric B-acute lymphoblastic leukaemia. Nat Commun. 2015;6:6604.

22. Waanders E, Gu Z, Dobson SM, Antic Z, Crawford JC, Ma X, et al. Mutational landscape and patterns of clonal evolution in relapsed pediatric acute lymphoblastic leukemia. Blood Cancer Discov. 2020;1:96-111.

23. Parry M, Rose-Zerilli MJ, Gibson J, Ennis S, Walewska R, Forster J, et al. Whole exome sequencing identifies novel recurrently mutated genes in patients with splenic marginal zone lymphoma. PLoS ONE. 2013;8:e83244.

24. Tausch E, Stilgenbauer S. BIRC3 mutations in chronic lymphocytic leukemiauncommon and unfavorable. Haematologica. 2020;105:255-6.

25. Staal FJ, Famili F, Garcia Perez L, Pike-Overzet K. Aberrant Wnt signaling in leukemia. Cancers. 2016;8:78.

26. Kennedy VE, Smith CC. FLT3 mutations in acute myeloid leukemia: key concepts and emerging controversies. Front Oncol. 2020;10:612880.

27. Walker BA, Mavrommatis K, Wardell CP, Ashby TC, Bauer M, Davies FE, et al. Identification of novel mutational drivers reveals oncogene dependencies in multiple myeloma. Blood. 2018;132:587-97.

28. Rehm A, Gatjen M, Gerlach K, Scholz F, Mensen A, Gloger M, et al. Dendritic cellmediated survival signals in Emu-Myc B-cell lymphoma depend on the transcription factor C/EBPbeta. Nat Commun. 2014;5:5057.
29. Harris AW, Pinkert CA, Crawford M, Langdon WY, Brinster RL, Adams JM. The E mu-myc transgenic mouse. A model for high-incidence spontaneous lymphoma and leukemia of early B cells. J Exp Med. 1988;167:353-71.

30. Nguyen L, Papenhausen P, Shao H. The role of c-MYC in B-cell lymphomas: diagnostic and molecular aspects. Genes. 2017;8:116.

31. Diop F, Moia R, Favini C, Spaccarotella E, De Paoli L, Bruscaggin A, et al. Biological and clinical implications of BIRC3 mutations in chronic lymphocytic leukemia. Haematologica. 2020;105:448-56.

32. Rossi D, Fangazio M, Rasi S, Vaisitti T, Monti S, Cresta S, et al. Disruption of BIRC3 associates with fludarabine chemorefractoriness in TP53 wild-type chronic lymphocytic leukemia. Blood. 2012;119:2854-62.

33. Hasan MK, Yu J, Widhopf GF 2nd, Rassenti LZ, Chen L, Shen Z, et al. Wnt5a induces ROR1 to recruit DOCK2 to activate Rac1/2 in chronic lymphocytic leukemia. Blood. 2018;132:170-8.

34. Hasan MK, Rassenti L, Widhopf GF 2nd, Yu J, Kipps TJ. Wnt5a causes ROR1 to complex and activate cortactin to enhance migration of chronic lymphocytic leukemia cells. Leukemia. 2019;33:653-61.

35. Lan Q, Au W-Y, Chanock S, Tse J, Wong K-F, Shen M, et al. Genetic susceptibility for chronic lymphocytic leukemia among Chinese in Hong Kong. Eur J Haematol. 2010;85:492-5.

36. McClanahan F, Hanna B, Miller S, Clear AJ, Lichter P, Gribben JG, et al. PD-L1 checkpoint blockade prevents immune dysfunction and leukemia development in a mouse model of chronic lymphocytic leukemia. Blood. 2015;126:203-11.

37. Qorraj M, Bruns H, Bottcher M, Weigand L, Saul D, Mackensen A, et al. The PD-1/ PD-L1 axis contributes to immune metabolic dysfunctions of monocytes in chronic lymphocytic leukemia. Leukemia. 2017;31:470-8.

38. Contri A, Brunati AM, Trentin L, Cabrelle A, Miorin M, Cesaro L, et al. Chronic lymphocytic leukemia $B$ cells contain anomalous Lyn tyrosine kinase, a putative contribution to defective apoptosis. J Clin Investig. 2005;115:369-78.

39. Amrein PC, Attar EC, Takvorian T, Hochberg EP, Ballen KK, Leahy KM, et al. Phase II study of dasatinib in relapsed or refractory chronic lymphocytic leukemia. Clin Cancer Res. 2011;17:2977-86.

40. Kwok M, Davies N, Agathanggelou A, Smith E, Oldreive C, Petermann E, et al. ATR inhibition induces synthetic lethality and overcomes chemoresistance in TP53- or ATM-defective chronic lymphocytic leukemia cells. Blood. 2016;127:582-95.

41. Yokota $S$, Kiyoi $H$, Nakao M, Iwai $T$, Misawa $S$, Okuda $T$, et al. Internal tandem duplication of the FLT3 gene is preferentially seen in acute myeloid leukemia and myelodysplastic syndrome among various hematological malignancies. A study on a large series of patients and cell lines. Leukemia. 1997;11:1605-9.

42. Cheng J, Qu L, Wang J, Cheng L, Wang Y. High expression of FLT3 is a risk factor in leukemia. Mol Med Rep. 2018;17:2885-92.

43. Tse KF, Mukherjee G, Small D. Constitutive activation of FLT3 stimulates multiple intracellular signal transducers and results in transformation. Leukemia. 2000;14:1766-76.

44. Stamatopoulos K, Belessi C, Moreno C, Boudjograh M, Guida G, Smilevska T, et al. Over $20 \%$ of patients with chronic lymphocytic leukemia carry stereotyped receptors: Pathogenetic implications and clinical correlations. Blood. 2007;109:259-70.

45. Jaramillo S, Agathangelidis A, Schneider C, Bahlo J, Robrecht S, Tausch E, et al. Prognostic impact of prevalent chronic lymphocytic leukemia stereotyped subsets: analysis within prospective clinical trials of the German CLL Study Group (GCLLSG). Haematologica. 2019;105:2598-607.

46. Dühren-von Minden M, Übelhart R, Schneider D, Wossning T, Bach MP, Buchner $M$, et al. Chronic lymphocytic leukaemia is driven by antigen-independent cellautonomous signalling. Nature. 2012;489:309-12.

47. Hayakawa K, Formica AM, Brill-Dashoff J, Shinton SA, Ichikawa D, Zhou Y, et al. Early generated B1 B cells with restricted BCRs become chronic lymphocytic leukemia with continued c-Myc and low Bmf expression. J Exp Med. 2016:213:3007-24

48. Kriangkum J, Motz SN, Mack T, Beiggi S, Baigorri E, Kuppusamy H, et al. Single-cell analysis and next-generation immuno-sequencing show that multiple clones persist in patients with chronic lymphocytic leukemia. PloS ONE. 2015;10: e0137232.

49. Langerak AW, Davi F, Ghia P, Hadzidimitriou A, Murray F, Potter KN, et al. Immunoglobulin sequence analysis and prognostication in CLL: guidelines from the ERIC review board for reliable interpretation of problematic cases. Leukemia. 2011;25:979-84.

50. Sanchez M-L, Almeida J, Gonzalez D, Gonzalez M, Garcia-Marcos M-A, Balanzategui $A$, et al. Incidence and clinicobiologic characteristics of leukemic B-cell chronic lymphoproliferative disorders with more than one B-cell clone. Blood. 2003;102:2994-3002

51. Lascano V, Guadagnoli M, Schot JG, Luijks DM, Guikema JEJ, Cameron K, et al. Chronic lymphocytic leukemia disease progression is accelerated by APRIL-TACI interaction in the TCL1 transgenic mouse model. Blood. 2013;122:3960-3. 
52. Gruber M, Bozic I, Leshchiner I, Livitz D, Stevenson K, Rassenti L, et al. Growth dynamics in naturally progressing chronic lymphocytic leukaemia. Nature. 2019;570:474-9.

53. Adams JM, Harris AW, Pinkert CA, Corcoran LM, Alexander WS, Cory S, et al. The c-myc oncogene driven by immunoglobulin enhancers induces lymphoid malignancy in transgenic mice. Nature. 1985;318:533-8.

54. Edelmann J, Holzmann K, Tausch E, Saunderson EA, Jebaraj BMC, Steinbrecher D, et al. Genomic alterations in high-risk chronic lymphocytic leukemia frequently affect cell cycle key regulators and NOTCH1-regulated transcription. Haematologica. 2020;105:1379-90.

55. Li Y, Hu S, Wang SA, Li S, Huh YO, Tang Z, et al. The clinical significance of $8 q 24 /$ MYC rearrangement in chronic lymphocytic leukemia. Mod Pathol. 2016;29:444-51.

56. Sadik A, Somarribas Patterson LF, Ozturk S, Mohapatra SR, Panitz V, Secker PF, et al. IL4I1 Is a metabolic immune checkpoint that activates the AHR and promotes tumor progression. Cell. 2020;182:1252-70.e34

57. Afzal S, Gil-Farina I, Gabriel R, Ahmad S, von Kalle C, Schmidt M, et al. Systematic comparative study of computational methods for $\mathrm{T}$-cell receptor sequencing data analysis. Brief Bioinform. 2019;20:222-34.

58. Turchaninova MA, Davydov A, Britanova OV, Shugay M, Bikos V, Egorov ES, et al. High-quality full-length immunoglobulin profiling with unique molecular barcoding. Nat Protoc. 2016;11:1599-616.

59. Dietrich S, Oles M, Lu J, Sellner L, Anders S, Velten B, et al. Drug-perturbationbased stratification of blood cancer. J Clin Invest. 2018;128:427-45.

\section{ACKNOWLEDGEMENTS}

We would like to thank Brigitte Schoell for performing the FISH analysis, Uta Höpken for providing $\mathrm{E} \mu-M y c$ samples, and Daniel Mertens for constructive discussion of data. This study was supported by the ERA-NET TRANSCAN-2 program JTC 2014-project FIRE-CLL. PMR has been funded by a fellowship of the DKFZ Clinician Scientist Program, supported by the Dieter Morszeck Foundation. SS was supported by the DFG (SFB1074 subproject B1).

\section{AUTHOR CONTRIBUTIONS}

SÖ designed the study, performed experiments, analyzed and interpreted data, prepared figures, and wrote the manuscript. YP performed bioinformatics analyses, interpreted data, prepared figures, and wrote the manuscript. SA performed bioinformatics analysis of RACE-PCR. IG-F performed RACE-PCR. AJ performed and analyzed FISH. P-MB analyzed the clinical data. VK, BH, and PMR performed experiments. LA interpreted data. MSch supervised RACE-PCR. SD provided clinical samples and information. SS and PL critically advised the study and reviewed the manuscript. $M Z$ designed and supervised the bioinformatics analyses, interpreted data, and wrote the manuscript. MS designed and supervised the study, interpreted data, and wrote the manuscript. All authors read and approved the final manuscript.

\section{FUNDING}

Open Access funding enabled and organized by Projekt DEAL.

\section{COMPETING INTERESTS}

The authors declare no competing interests.

\section{ADDITIONAL INFORMATION}

Supplementary information The online version contains supplementary material available at https://doi.org/10.1038/s41375-021-01381-4.

Correspondence and requests for materials should be addressed to M.S.

Reprints and permission information is available at http://www.nature.com/ reprints

Publisher's note Springer Nature remains neutral with regard to jurisdictional claims in published maps and institutional affiliations.

(i) Open Access This article is licensed under a Creative Commons Attribution 4.0 International License, which permits use, sharing, adaptation, distribution and reproduction in any medium or format, as long as you give appropriate credit to the original author(s) and the source, provide a link to the Creative Commons license, and indicate if changes were made. The images or other third party material in this article are included in the article's Creative Commons license, unless indicated otherwise in a credit line to the material. If material is not included in the article's Creative Commons license and your intended use is not permitted by statutory regulation or exceeds the permitted use, you will need to obtain permission directly from the copyright holder. To view a copy of this license, visit http://creativecommons. org/licenses/by/4.0/.

(c) The Author(s) 2021 